of a larger 'sink' for carbon or by a combination of both effects.

Irrespective of its physiological basis, it is clear that differences in functional compatibility can explain both the stimulatory effect on individual plant species and the influence of fungal species diversity upon the overall structure of the plant community. In the experimental system of van der Heijden et al. ${ }^{4}$, plant diversity reached a maximum when eight fungal species were added - a number that must in part reflect the physical and biological constraints of the authors' reconstructed communities. It would take a brave person to propose a likely optimal number under field conditions, and a rash one to suggest, at this stage of our understanding, that any symbiont might be redundant.

Although debate continues over the contribution of diversity to ecosystem function, empirical studies provide support for the view that floristically rich systems are more productive $^{7}$, show greater stability under stress $^{8}$ and are more likely to provide alleviation of global problems posed by atmospheric $\mathrm{CO}_{2}$ enrichment ${ }^{9}$. A recognition of these properties, coupled with an increasing awareness that the diversity of terrestrial vegetation systems is everywhere under threat, has forced biologists to consider the mechanisms that determine species composition in plant communities.

The study of van der Heijden et al. high- lights the essentially interactive nature of those mechanisms. It also shows that conservation of the fungal gene pool is likely to be a prerequisite for maintenance of floristic diversity in grasslands, as well as in other ecosystems such as boreal forests ${ }^{10}$, where the fungal web is known to influence allocation of resources between plant species. We are already aware of many of the sensitivities of the mycorrhizal community to perturbations, particularly those associated with cultivation and nutrient enrichment ${ }^{11}$. So the new findings may be of direct practical importance for those managers who seek to optimize floristic diversity, be it for environmental, conservation or amenity purposes.

David Read is in the Department of Animal and

Plant Sciences, University of Sheffield,

Sheffield S10 2TN, UK.

e-mail:D.J.Read@sheffield.ac.uk

1. Smith, S. E. \& Read, D. J. Mycorrhizal Symbiosis 2nd edn (Academic, San Diego, 1997).

2. Fitter, A. H. New Phytol. 79, 119-125 (1977).

3. Grime, J. P., Mackey, J. M. L., Hillier, S. H. \& Read, D. J. Nature 328, 420-422 (1987)

4. van der Heijden, M. G. A. et al. Nature 396, 69-72 (1998)

5. Whittaker, R. H. Communities \& Ecosystems 2nd edn (Macmillan, New York, 1975).

6. Ravnskov, S. \& Jakobsen, I. New Phytol. 129, 611-618 (1995).

7. Tilman, D., Wedin, D. \& Knops, J. Nature 379, 718-720 (1996).

8. Tilman, D. \& Downing, J. A. Nature 367, 363-365 (1994)

9. Naeem, S., Thompson, L. J., Lawler, S. P., Lawton, J. H. \&

Woodfin, R. M. Nature 368, 734-737 (1994).

10.Simard, S. W. et al. Nature 388, 579-582 (1997).

11. Helgason, T., Daniell, T. J., Husband, R., Fitter, A. H. \& Young, J. P. Y. Nature 394, 431 (1998).

\title{
Bumps on the road to immortality
}

Robert A. Weinberg

n contrast to normal cells, which double only a limited number of times in culture, almost all malignant tumour cells can double indefinitely. Telomeres — specialized structures at the end of chromosomes - seem to be central molecular determinants of this immortality trait, and their role is addressed by Kiyono etal. ${ }^{1}$ on page 84 of this issue.

Telomeric DNA is essential to preserve the ends of chromosomes and, hence, the integrity of the genome. According to one model ${ }^{2}$, in normal cells telomeres shorten with each generational doubling. Ultimately they erode to a size that causes cells to senesce or, if the cells manage to circumvent this initial blockade, to enter into crisis (when karyotypic instability accompanies, and probably causes, widespread death in cell populations). But expression of telomerase, an enzyme that is repressed in most post-embryonic human cells, allows cells to repair their telomeres. In this way cancer cells can subvert the generational clock, avoiding senescence or crisis, and achieve unlimited proliferation.

This model received strong support from a landmark paper ${ }^{3}$ published this January, in which the ectopic expression of hTERT the catalytic subunit of the telomerase holoenzyme - enabled human cells that were destined to senesce to multiply indefinitely $^{3,4}$. Thus, ectopic expression of $h T E R T$ seems to have allowed these cells - retinal pigmented epithelial (neuorectodermal) cells and fibroblasts - to avoid both senescence and the subsequent crisis.

This result was a Holy Grail for many cell biologists, who have wrestled unsuccessfully with the difficulties of propagating differentiated cells from various tissues in culture. Almost invariably such cells stop growing victims of senescence. To try and immortalize primary cells, some workers have introduced viral oncogenes such as the SV40 large $\mathrm{T}$ antigen oncogene into them. Indeed, SV40 large $\mathrm{T}$ is known to allow cells to circumvent senescence ${ }^{5}$. However, although this trick may extend life span, the resulting cell cultures often represent a pyrrhic victory because the immortalizing agent also perturbs their differentiation programmes. In contrast, ectopic expression of telomerase promises to confer replicative immortality on

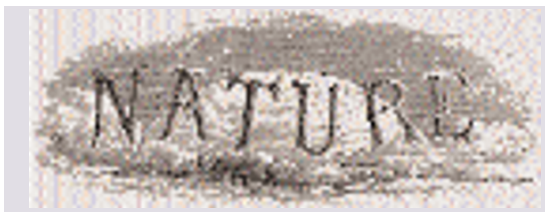

100 YEARS AGO

The introduction of electricity into our houses has added materially to the comfort and luxury of home. If we were living in the days of ancient Greece, the presiding domestic deity would have been Electra. The old bellhanger has been rung out by the new goddess. Electra ...

attracts the attention of our domestics, not by a gamut of ill-toned and irregularlyexcited bells, but by neat indicators and one uniform sound. The timid visitor fears no more that he has expressed rage or impatience by his inexperience of the mechanical pull required at the front door. The domestic telephone is coming in as an adjunct to the bell. Its use saves two journeys. The bell attracts attention, the telephone transmits the order ... Heating appliances are becoming very general ... Radiators assist the coal fire by maintaining the temperature of a room uniform throughout its length and breadth. Ovens are heated, water is boiled, flatirons become and are maintained at a useful temperature, breakfast dishes and tea-cakes are kept hot, even curling-tongs have imparted to them the requisite temperature to perform their peculiar function.

From Nature 3 November 1898.

\section{YEARS AGO}

The award of the Nobel Prize for Medicine for 1948 has been made to Dr. Paul Müller for his discovery of the effects as an insecticide of D.D.T. Drs. P. Läuger, P. Müller and H. Martin were the leaders of an intensive research for insecticidal chemicals in the Basle laboratories of J. R. Geigy, S.A., which extended more than twenty years. The researches were directed originally towards the discovery of moth-proofing agents ... It seems to have been in the course of field trials that its remarkable effectiveness against the Colorado beetle was noticed. It was soon found to be equally toxic to the louse and the mosquito. The material was brought to the notice of medical entomologists ... at a critical moment in the War when the supplies of pyrethrum were rapidly falling short of the demand ... It proved of enormous value in combating typhus and malaria during the War, and now it is being employed with success in campaigns for the complete eradication of malaria from island areas. From Nature 6 November 1948. 
cells without affecting other regulatory systems such as those that control differentiation.

But the work of Kiyono et al. ${ }^{1}$ now indicates that it may not be so easy to avoid senescence, at least in certain cell types. Their work with two human epithelial cell types keratinocytes and mammary epithelial cells — indicates that immortalization of these cells requires expression of the hTERT gene and inactivation of the retinoblastoma $(\mathrm{Rb}) / \mathrm{p} 16^{\mathrm{INK} 4 \mathrm{a}}$ tumour-suppressor pathway. This pathway halts cells in the G1 phase of the cell cycle in response to a range of physiological signals known to inhibit growth (Fig. 1).

These results highlight the complexity of the senescence phenotype. The very name is misleading, because senescence is provoked by many stimuli that have nothing to do with cell ageing. For example, activation of oncogenes can induce a cell to senesce rapidly ${ }^{6}$. Hence, telomere shortening cannot be the only stimulus to provoke senescence. This conclusion is made obvious by the observation that when primary cells are placed into culture they often senesce within a small number of generations - long before their telomeres have eroded significantly.

Such observations might indicate that the senescence phenotype signals the difficulties that cells experience when they are explanted from living tissue into the artificial environment of the culture dish. Physiological stress may, for example, activate the $16^{\text {INK4a }}$ cyclindependent kinase inhibitor, which in turn shuts down growth by blocking phosphorylation of Rb. Hence, senescence provoked by dif-

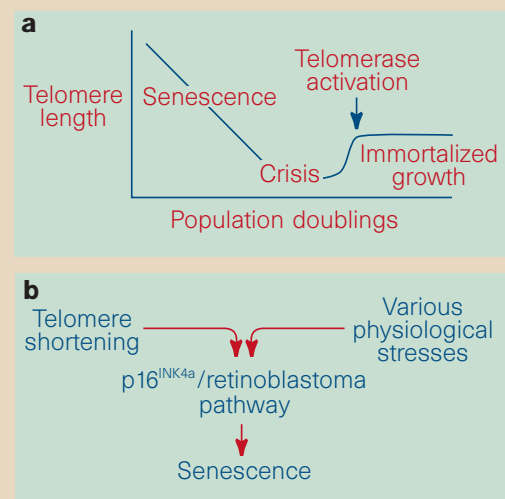

Figure 1 Models for the role of telomeres in cell immortalization. a, Standard model. With each cell division, the telomeres at the end of the chromosomes become shortened. In normal cells this leads to senescence and eventually to crisis. But activation of telomerase, in cancer cells for example, allows the telomeres to be regenerated indefinitely, immortalizing these cells. b, Revised model, according to the results of Kiyono et al. ${ }^{1}$. They show that activation of telomerase alone is not enough to immortalize certain epithelial cells, and that inactivation of the $\mathrm{p} 16^{\mathrm{INK} 4 \mathrm{a}} /$ retinoblastoma pathway is also needed. Because this pathway is activated by many other physiological stresses, immortalizing cells may not be as simple as was previously thought. ficulties in adapting to a culture medium may be avoided only by neutralizing the p16 ${ }^{\text {INK4a }} / \mathrm{Rb}$ braking system. Kiyono et al. ${ }^{1}$ exploit human papillomavirus oncoproteins to doso, but the SV40 large T oncoprotein used by others seems to achieve the same result ${ }^{5}$.

All this converges on the idea that the epithelial cells studied by Kiyono et al. and, perhaps, all epithelial cells — may need to overcome the senescence induced by explantation into culture before they confront the barrier to unlimited proliferation of telomere shortening. Such a sequence of events might explain why inactivation of the $\mathrm{Rb}$ pathway and ectopic expression of telomerase are both required for immortalization of epithelial cells. For those intent on using hTERT to immortalize primary epithelial cells and study their differentiation phenotypes, this model, if extended and validated, will have unfortunate consequences because inactivation of the $\mathrm{Rb}$ pathway often affects differentiation programmes ${ }^{7}$.

This work may also affect our view of how tumours progress in the $90 \%$ of human cancers that derive from epithelia. Cell immortalization may be a two-step process at the least. The first step, inactivation of the p16 $6^{\mathrm{INK} 4 \mathrm{a}} / \mathrm{Rb}$ pathway, may occur relatively early, enabling cells to avoid the senescence provoked by, for example, oncogene activation ${ }^{6}$. Only later in tumour progression, when clones of premalignant cells have begun to exhaust their endowment of telomeres, will activation of telomerase through derepression of hTERT become advantageous for further proliferation.

Moreover, the apparent separation between oncogenes, tumour-suppressor genes and $h T E R T$ may be an illusion. A recent study $^{8}$ indicates that the $m y c$ oncogene upregulates telomerase expression, and the work of Kiyono et al. ${ }^{1}$ and earlier work of others ${ }^{9}$ shows that the E6 oncogene of the human papillomavirus can induce expression of hTERT. Accordingly, the circuitry that governs the cell-cycle clock may be tightly linked to that governing the telomere-based generational clock. Thus, oncogene activation may yield both short-term advantages in deregulating advance of the cell cycle and long-term advantages by stabilizing telomeres.

Robert A. Weinberg is at the Whitehead Institute for Biomedical Research, and the Department of Biology, Massachusetts Institute of Technology, Cambridge, Massachusetts 02142, USA.

e-mail:weinberg@wi.mit.edu

\section{Kiyono, T. et al. Nature 396, 84-88 (1998).}

2. Sedivy, J. M. Proc. Natl Acad. Sci. USA 95, 9078-9081 (1998).

3. Bodnar, A. G. M. et al. Science 279, 349-352 (1998).

4. Vaziri, H. \& Benchimol, S. Curr. Biol. 8, 279-282 (1998).

5. Wright, W. E. \& Shay, J. W. Exp. Gerontol. 27, 383-389 (1992).

6. Serrano, M., Lin, A. W., McCurrach, M. E., Beach, D. \& Lowe, S. W. Cell 88, 593-603 (1997).

7. Jacks, T. \& Weinberg, R. A. Science 280, 1035-1036 (1998).

8. Wang, J., Xie, L. Y., Allan, S., Beach, D. \& Hannon, G. J. Genes Dev. 12, 1769-1774 (1998).

9. Klingelhutz, A. J., Foster, S. A. \& McDougall, J. K. Nature 380, 79-82 (1996).

\section{Daedalus \\ Smokeless microwaves}

A flame keeps burning by thermal feedback. The heat it gives out vaporizes incoming fuel, and raises it to combustion temperature. Sadly, the process is not particularly efficient. Vaporized fuel is never completely burnt in its passage through the flame. A little unburnt fuel, and a variety of partly burnt combustion products, always escape into the cooling flue gases. The result is soot, smoke, and frequently the need for a costly catalytic converter downstream, to oxidize the pollutants before they get away.

So Daedalus is planning an alternative form of energetic feedback. His idea is to beam intense microwaves into the burner or furnace. The hot, ionized combustion gases should be conducting enough to absorb the energy, which will make them hotter still. The beam should be concentrated just above or beyond the flames, to heat and oxidize the partially burnt gases before they can cool down. Visible smoke, in the form of carbonaceous particles, will be particularly well suppressed. Carbon is such a good conductor that the microwaves will keep it glowing until it has burnt completely. But microwaves seem to encourage chemical reactions not merely by heating, but also by direct molecular agitation. Nasties such as carbon monoxide and nitric oxide absorb them strongly, and should be rapidly reacted away.

The obvious application is to big power-stations. They could well afford to boost their combustion efficiency by feeding a bit of power back into their furnaces. Old, polluting coal-fired stations, and ecologically virtuous ones heroically trying to burn rubbish, would benefit the most. Indeed, even the Greens might applaud a guaranteed pollutionfree, microwave-augmented incinerator.

The internal-combustion engine is a more daring challenge. DREADCO engineers are now plumbing microwave waveguides into the cylinders of a test diesel engine. A dynamo on the engine will power a klystron. At each moment of ignition, it will beam an intense microwave pulse into the firing cylinder, which will act as a frequency-swept resonant cavity. Smoke and partialcombustion products should vanish. They will be burned, not in a wasteful exhaust catalyser, but in the engine itself, thus raising its efficiency. Even the microwave energy beamed into the cylinders will boost the engine's power, and be partly returned to the dynamo generating it. David Jones 